\title{
Spatial analysis of the mining and transport of rock minerals (aggregates) in the context of regional development
}

\author{
Jan Blachowski
}

Received: 19 August 2012/Accepted: 8 May 2013/Published online: 17 May 2013

(C) The Author(s) 2013. This article is published with open access at Springerlink.com

\begin{abstract}
Rock minerals such as dimension and crushed stones and sands and gravels (aggregates) are indispensable materials for the building and construction industries. The growth in demand for these resources causes intensification of mining operations (and their consequent environmental impacts) and transport problems in regions abundant in rock minerals. The balanced management of these resources by regional policy-makers is difficult as it requires, among other things, comprehensive and up-to-date information on the spatial distribution and temporal changes of available reserves, demand, production, and transport. This information can be provided by means of spatial and temporal analyses through geographic information systems (GIS). In this research, the focus is on the following aspects of rock mineral (aggregates) resources and mining management in the context of regional spatial planning in the example region of Lower Silesia in Poland: the spatial and temporal changes in distribution and intensity of mining, the availability of economic reserves in active mines, the magnitude and distribution of road transport flows of aggregates, the potential of railways as an alternative means of transport, and the valorisation of undeveloped aggregates deposits to assess their suitability for future use. For the purposes of this study, cartographic models have been developed using GIS to facilitate analyses of these mineral resources, mining, and transport. The results of these analyses provide current and comprehensive information on the state of aggregates mineral resources, production and transport in the Lower Silesia region. They
\end{abstract}

J. Blachowski ( $\square)$

Wroclaw University of Technology, Institute of Mining

Engineering, Wybrzeże Wyspiańskiego 27,

50-370 Wrocław, Poland

e-mail: jan.blachowski@pwr.wroc.pl also give an insight into availability of rock mineral resources for the future. Knowledge of these processes is important for spatial development planning, especially physical infrastructure, conducted by national, regional, and local governments.

Keywords Rock minerals - Mining - Transport · Spatial analysis · GIS · Regional development

\section{Introduction}

Rock minerals such as dimension and crushed stones and aggregates (sands and gravels) are raw materials vital for the construction of buildings, roads, and other types of infrastructure. For simplicity, in this paper the term "aggregates" will be used to cover all of these various types of rock mineral raw materials. Deposits of these raw materials, the locations of which are conditioned by geology, are usually unevenly distributed across any given area (e.g., region or a country). This is especially true for magmatic, metamorphic and sedimentary dimension, and crushed stones. Deposits of sands and gravels are more common and widely distributed. On the other hand, in many cases, the users of these materials, e.g., road construction sites and large cities, may be located at considerable distances away, even hundreds of kilometers, from available sources. The demand for aggregates results in pressure to increase output from existing sources and to start new mining operations. This in turn increases loads on communication networks (i.e., road and railways) used to transport these materials from sources to receiver areas.

The typical means of transport for aggregates are railways and roads. Road transport, using tipper and semitrailer tipper trucks is usually appropriate for shorter 
distances (i.e., tens of $\mathrm{km}$ ), whereas rail transport is used for longer distances (i.e., hundreds of kilometers). The factors determining the use and cost of both types have been analysed elsewhere, e.g., by Łochańska and Stryszewski (2011). These include, most importantly: the structure of supply and demand for aggregates, availability of transport network infrastructure, and the cost of transport (usually given per $\mathrm{km}$ ). However, often the type of transport used may be determined by the availability of a given network in the vicinity of the mined deposit.

The development of new deposits is determined by constraints such as: land use, environmental protection considerations (e.g., nature protection areas), connectivity to transport networks, geological and mining conditions, quality of rocks, quantity and uniqueness of rock minerals. The value of aggregates deposits for development can be assessed using various valorisation methods. The most comprehensive concept of deposit valorisation has been proposed by Radwanek-Bạk (2007) and Nieć and Radwanek-Bạk (2011). This is based on four criteria: geological assets, mining conditions, environmental aspects, and spatial planning constraints; these are assessed from information in available deposit documentation, resulting in a four letter classification being assigned to a deposit describing its suitability for development.

The sustainable development of available aggregates resources requires, among other things, information on the current and future supply and demand for these rock raw materials. This is significant for the effective spatial planning of development in regions characterised by large and diversified resources of rock minerals as these regions often are the reservoirs of aggregate resources for other, less abundantly endowed, areas. The producer regions then experience the environmental, economic, and social impacts arising from increased mining and transport activity.

Studies related to this subject focus mainly on the environmental impact assessment of mining. Vrba and Moldan (1989) have proposed the concept of a single multicomponent space for the integrated use of natural resources and the geo-environment. Jordan (2009) has written about spatial contamination risk assessments of mining and how geological knowledge can be transferred to the environmental assessment of mines and quarries based on experiences from various European countries. The recent work by Huang et al. (2012) proposes a multiple-criteria assessment method integrating a fuzzy logic concept into the geo-environmental impact assessment of mining. Whereas Bagdanavičiūtè and Valiūnas (2012) have applied GIS and multi-criteria-based methodology for land use suitability analysis that included environmental, economic, and geological conditions. In this paper, the proposed methodology is an enhancement of these studies, taking into account also other factors associated with aggregate quarrying, including transport and resource availability constraints. The study also takes advantage of geographic information systems (GIS) to obtain a comprehensive and visual picture of the spatial context for the regional development of aggregates.

The spatial characteristics of the mining and transport of aggregates predispose analysis towards GIS-based analytical functions in order to facilitate investigations of these phenomena. The aim of the study has been to analyse, with the use of cartographic modelling in GIS, the following issues:

- the spatial and temporal changes in the distribution and intensity of aggregates extraction,

- the magnitude of the sources of rock minerals road transport streams,

- the potential of railways to transport aggregates,

- the availability (in years) of aggregates mineral reserves in active quarrying operations,

- the general valorisation of undeveloped aggregates deposits.

The application of cartographic modelling, a method of spatial data processing that generates new spatial data based on input data (treated as spatial variables) and operations performed on them (Heywood et al. 2006), facilitated analyses of the spatial distribution and temporal changes of aggregates availability, production, demand, and transport. The methodology used in these studies can be applied to other topics of interest.

This paper focuses on the case of Lower Silesia (Dolnoslaskie), one of 16 administrative regions in Poland, and the principal provider of magmatic and metamorphic dimension and crushed stones in the country. At the present time, this region is experiencing increased demand for these raw materials, which are used for road, railway, and building construction purposes. The period analysed covers the past 5 years (2006-2010). The results of these investigations have been used in drafting a revised spatial development plan and spatial development strategy for Lower Silesia, as well as a programme for the adaptation of the railway infrastructure to service the transport of aggregates from Lower Silesia to elsewhere.

\section{Road and building material quarrying in Poland and in Lower Silesia}

The last decade has seen a growth of demand for aggregates in Poland because of the modernisation of the national road infrastructure and the growth of the housing and building construction industry. The production dimension and crushed stones has almost tripled and 
Table 1 Production of dimension and crushed stones and sand and gravels in Poland in the 2001-2010 period (Polish Geological Institute 2011)

\begin{tabular}{|c|c|c|c|c|c|c|c|c|c|c|}
\hline & 2001 & 2002 & 2003 & 2004 & 2005 & 2006 & 2007 & 2008 & 2009 & 2010 \\
\hline DCS & 22,112 & 22,619 & 25,689 & 28,704 & 33,834 & 36,603 & 45,534 & 50,914 & 55,280 & 63,224 \\
\hline SG & 73,107 & 66,722 & 78,970 & 81,398 & 96,966 & 116,693 & 139,538 & 150,034 & 141,037 & 163,441 \\
\hline
\end{tabular}

Production given in thousand tonnes

$D C S$ dimension and crushed stones, $S G$ sand and gravel

production of sands and gravels more than doubled in the past 10 years (2001-2010) as shown in Table 1 . This trend in demand is expected to last for at least another decade. The projected demand for aggregates for road and rail construction is estimated at 230 million tonnes between 2012 and 2020 (190 million tonnes for roads and 40 million tonnes for railway construction) and this constitutes between 15 and $25 \%$ of the total demand for these materials in Poland (Kabzinski 2012).

With 406 documented sand and gravel and 272 documented dimension and crushed stones deposits, the Lower Silesia region accounts for more than half of the annual national production of such materials, including over $90 \%$ (91.6\% in 2010) of the magmatic and metamorphic stone production in Poland (PGI 2011). This makes the region the most important producer area in the country.

The Lower Silesia region, with an area of 19 $946.7 \mathrm{sq} \mathrm{km}$, is one of the 16 administrative units of Poland. It is located in the SW part of the country bordering the Czech Republic to the south and Germany to the west.

Nature protection areas constitute $18.2 \%$ of the region's total surface and when Nature 2000 sites are included this percentage rises to $35 \%$ (CSO 2011). The road and railway transport networks are at their highest density in the country but their technical condition, especially the railway system, remains poor and requires further planned investment (Blachowski et al. 2012).

\section{Materials and methods}

The aim of the paper is to study the spatial and temporal changes in aggregates resource distribution, mining and transport in the Lower Silesia region; procedures utilising cartographic modelling functions in GIS are proposed and used. Cartographic modelling, uses spatial data as variables that are subjected to algebraic operations. A cartographic model transforms or combines spatial data (maps) to produce new data by the use of specific statistical operations and to solve spatially related problems (Tomlin 2008; Kennedy 2009).

The methodology of each spatial analysis, performed using ESRI ArcGIS v. 10 software, is described below. Vector type datasets representing quarry and deposit locations, nature protection areas, land use, underground water, railway and road networks have been used as source data in these analyses.

Density of rock minerals production

The first analysis concerns the density of aggregates production and changes in time. It has been performed using the Epanechnikov quadratic Kernel function (McCoy et al. 2004). Kernel is a weighting function used in non-parametric estimation such as density estimation to calculate a variable density function (in this case rock raw material production). The general function is given by the following formula (Epanechnikov 1969):

$f_{\lambda}(x)=\frac{1}{n \lambda} \sum K_{0}\left(\frac{x-x_{i}}{\lambda}\right)$

where $K_{0}$ is the Kernel function, $\lambda$ is the bandwidth (smoothing parameter), which determines the width of neighbourhood and degree of smoothness.

Quadratic kernel function has the form of

$K_{0}(t)= \begin{cases}0.75\left(1-t^{2}\right) & \text { for }|t| \leq 1 \\ 0 & \text { otherwise }\end{cases}$

The result of applying the Kernel density function in GIS is a smoothly curved surface that is fitted over each point representing magnitude per unit area of the analysed variable (McCoy et al. 2004).

The input parameters include: spatial location, population field value, and the search radius. The point locations of all quarries (300) and their annual output, as the population field value (in tonnes), have been used as input data for this analysis. The surfaces representing the density of aggregates production per unit area $\left(\mathrm{km}^{2}\right)$ have been calculated for the years 2006 to 2010 . The pixel size of each output raster surface is $100 \times 100 \mathrm{~m}$ and a search radius of $20,000 \mathrm{~m}$ has been used. The results are shown and discussed in "Density of rock minerals production".

\section{Scale of road transport flows for aggregates}

The principal originating locations of the road transport of aggregates are quarries and processing plants. In this analysis, the location and size of these origins have been 
calculated based on their daily and annual production; the information comes from the regional mining authority and surveys covering the types of transport used by the quarries (rail, road, or mixed). The size of road transport originating locations has been expressed as the daily and annual number of trucks necessary to carry aggregates from the originating locations (quarries) to receiver areas (construction sites). The quarries have been differentiated on the basis of the type of transport used: road, rail and mixed.

As a first step, for the quarries using road transport only, daily production has been calculated, dividing the annual output by the number of working days in a given year. Next, the number of trucks has been calculated, dividing daily production by the standard capacity of a haulage truck used to transport aggregates. In the case of quarries using mixed transport, a known fraction of the output has been used to calculate the number of trucks required. In the case of mines using rail transport, a fraction representing $10 \%$ of the output has been used to account for the local road transport of aggregates.

Furthermore, the quarries with rail sidings on premises and quarries transporting rock minerals to a nearby loading point have been differentiated. The numbers of trucks, calculated by the above process, have been used as the population field to determine the magnitude per unit area of road transport using the Kernel density function. The results are presented and discussed in "Scale of road transport flows for aggregates".

\section{Potential of railways to transport aggregates}

In another work, the potential of the railway network to transport aggregates has been studied. The adopted methodology identified quarries that use road transport in a search radius of up to $5 \mathrm{~km}$ (at a $1 \mathrm{~km}$ interval) from the railway loading stations, using a spatial analysis buffering function. This function is commonly used for proximity analysis and creates buffer zones around selected objects at a specified radius or radii in case of multiple buffers. Next, statistics have been calculated for each railway loading station including its potential capacity and the total output from the identified quarries in its neighbourhood. In the same way, the potential of closed railway lines to carry aggregates has been estimated. The results of this analysis are described in "Potential of railways to transport aggregates".

\section{Sufficiency of aggregates reserves}

The next analysis estimated how long, in years, the mineral reserves of active quarrying operations will last at a given output level. For this purpose, the mean annual production of each quarry has been calculated based on average outputs for the past 5 years (2006-2010). Once this value has been obtained, several scenarios of aggregates demand have been analysed, ranging from a $20 \%$ increase to a $30 \%$ decrease in production. The following formula has been used.

$S_{m}=\frac{R_{m}}{K \times P_{m}}$

where $S_{m}$ is a size of mineral reserves of $m$ mine, $R_{\mathrm{m}}$ is a economic reserves-technically and economically extractable part of economic resources (PGI 2011) of $m$ mine, $P_{\mathrm{m}}$ is a averaged annual production of $m$ mine, $k$ parameter representing annual production scenarios in the range 0.7-1.2.

The reserve sufficiency of a given mineral type (e.g., granite) has been calculated taking into account the total economic reserves that are the technically and economically extractable parts of economic resources according to a national classification (PGI 2011) or category 221 according to the UNCF-2009 classification (UN 2010); and the total averaged production of the mineral using the above equation. Calculations have been done in ArcGIS using a table field calculator and Visual Basic Script functions. The results are shown and described in "Sufficiency of aggregates reserves".

\section{Valorisation of aggregates deposits}

Valorisation can be thought of as assigning values to objects, e.g., an undeveloped mineral deposit, based on selected criteria. In a subsidiary study, an analysis has been conducted to obtain a classification of undeveloped aggregates deposits, characterising their suitability for development, using a GIS cartographic model based on a modification of the valorisation concept proposed by Radwanek-Bạk (2007) and Nieć and Radwanek-Bạk (2011). The modified method includes the following ranking criteria: environmental and land use constraints, the quality and quantity of geological reserves, and the transport accessibility of the deposit. The environmental constraints include location within or in the proximity to nature protection areas, forests, or underground water reservoirs. The land-use constraints include: arable land, orchards, and developed areas (e.g., settlements). The transport criterion focuses on proximity to railway network. In contrast to Nieć and Radwanek-Bąk (2011), the deposits located in the proximity of a railway system have been assigned higher scores than a road system as this form of transport is preferred.

This analysis results in four values: environmental score, land-use score, geological reserves (taking into account potentials of other sources of a given mineral in the country) score, and transport option score. Based on these values, four symbols have been assigned to each deposit in a manner similar to the one proposed by Nieć and Radwanek-Bạk (2011). The scores have been calculated using 
cartographic modelling procedures developed in GIS. This facilitates and streamlines the otherwise time consuming and tedious operations. The cartographic modelling technique is explained through the example of calculating the environmental score. This consists of a set of subsequent spatial operations that, first, determines if undeveloped deposits coincide with various forms of nature protection areas (i.e., nature reserves, landscape parks, areas of protected landscape), underground water reservoirs, and forests. Based on the type of coincidence, expressed in terms of percentage of overlapping areas, three sub-scores are calculated. Depending on the value of the sum of these subscores (2-6), the magnitude of the conflict is determined in terms of environmental protection requirements; thus a symbol representing an adequate category is assigned. The possible categories are: deposits unavailable for development (C), deposits conditionally available (B), and deposits accessible without restrictions (A). The criteria proposed in this part of valorisation excluded deposits within the boundaries of protected areas and protected underground water reservoirs $(\mathrm{C})$ thus are more conservative than those proposed by the abovementioned authors. In the case of forests and arable land, the scores were assigned based on the fraction of the deposit area falling within these areas (30, 31-90, and over $90 \%)$. Deposits coinciding with orchards or built-up areas were excluded and assigned the C category (unavailable for development). The diagram showing part of the modelling procedure used to determine the sub-score for nature protection areas is shown in Fig. 1.

To calculate the geological reserve score, the proven quantity of mineral in the deposit and its uniqueness (existence of other documented deposits) has been used. The larger the deposit, the higher the score that has been given.
The transport score used the distance from railway lines and railway loading points (up to $5 \mathrm{~km}$ away). The results are shown and described in (Valorisation of aggregates deposits).

\section{Results and discussion}

The results of these analyses of the spatial distribution and of temporal changes in aggregates quarrying and transport in the Lower Silesia region, as well as a simplified valorisation of deposits, are discussed below.

\section{Density of rock minerals production}

The maps of rock mineral production density between 2006 and 2010 are shown in Fig. 2 (Blachowski 2011). The maps show that the most intensive quarrying takes place in the southern, south-eastern, and central part of the Lower Silesia region. This is determined by regional geology and the consequent location of exploitable deposits. The growth of mineral output represented by more intensive (darker) colours in successive years (2006-2010) is related to the rise in production from the region's quarries; the overall regional increase was $70 \%$ or 12,532 thousand tonnes in the case of dimension and crushed stones and $21 \%$ or 2,510 thousand tonnes for sand and gravels.

Analysing the density of production maps in more detail, a slow shift of the highest production zones from the southern and central parts in an easterly direction can be observed between 2006 and 2010. This may be attributed to increased output from mines located in the south-eastern and the eastern parts of the Lower Silesia, as well as opening up new mining operations in these areas.

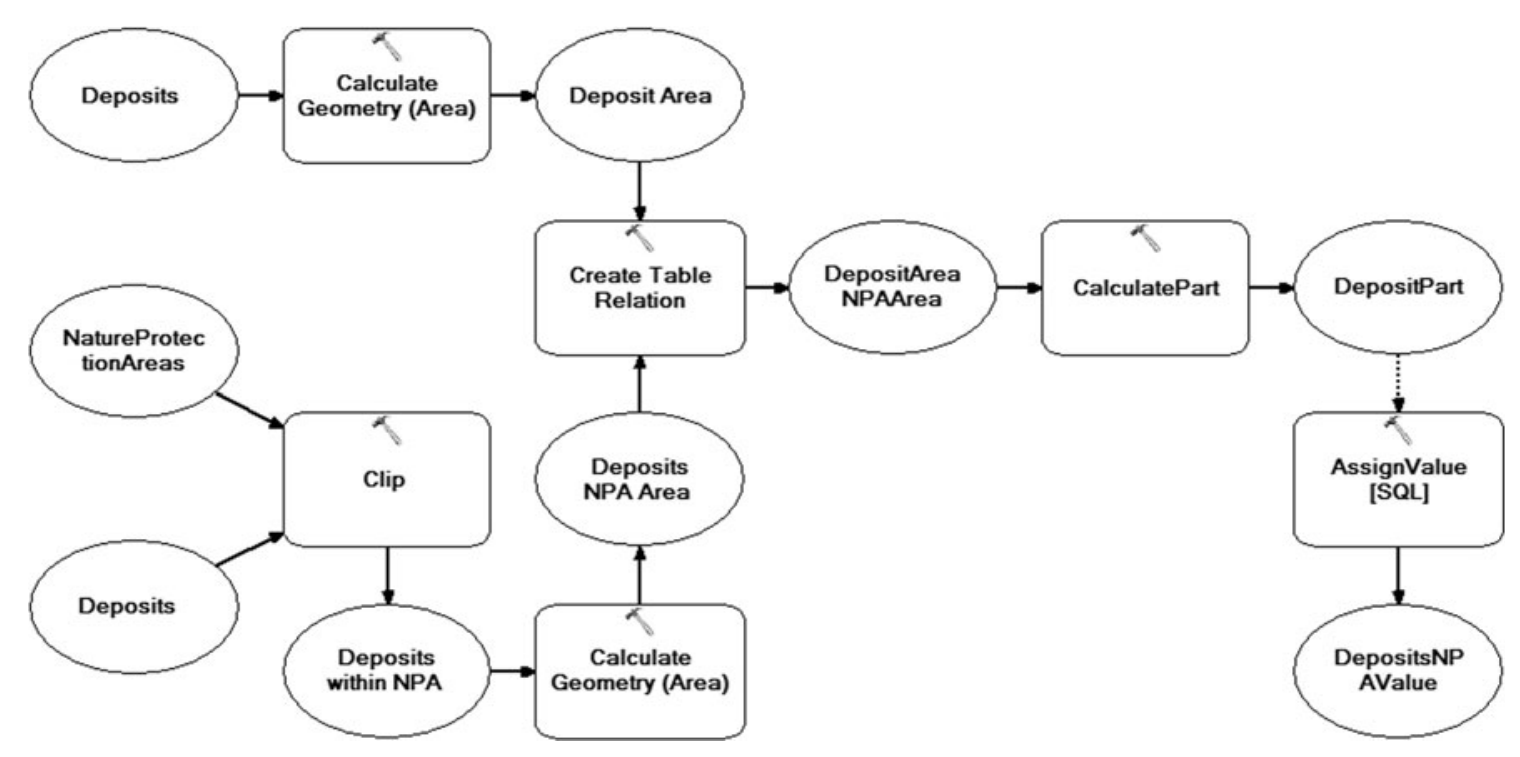

Fig. 1 Diagram of the environmental part of the valorisation cartographic model in GIS 
Fig. 2 Density of production of rock minerals (2006-2010)
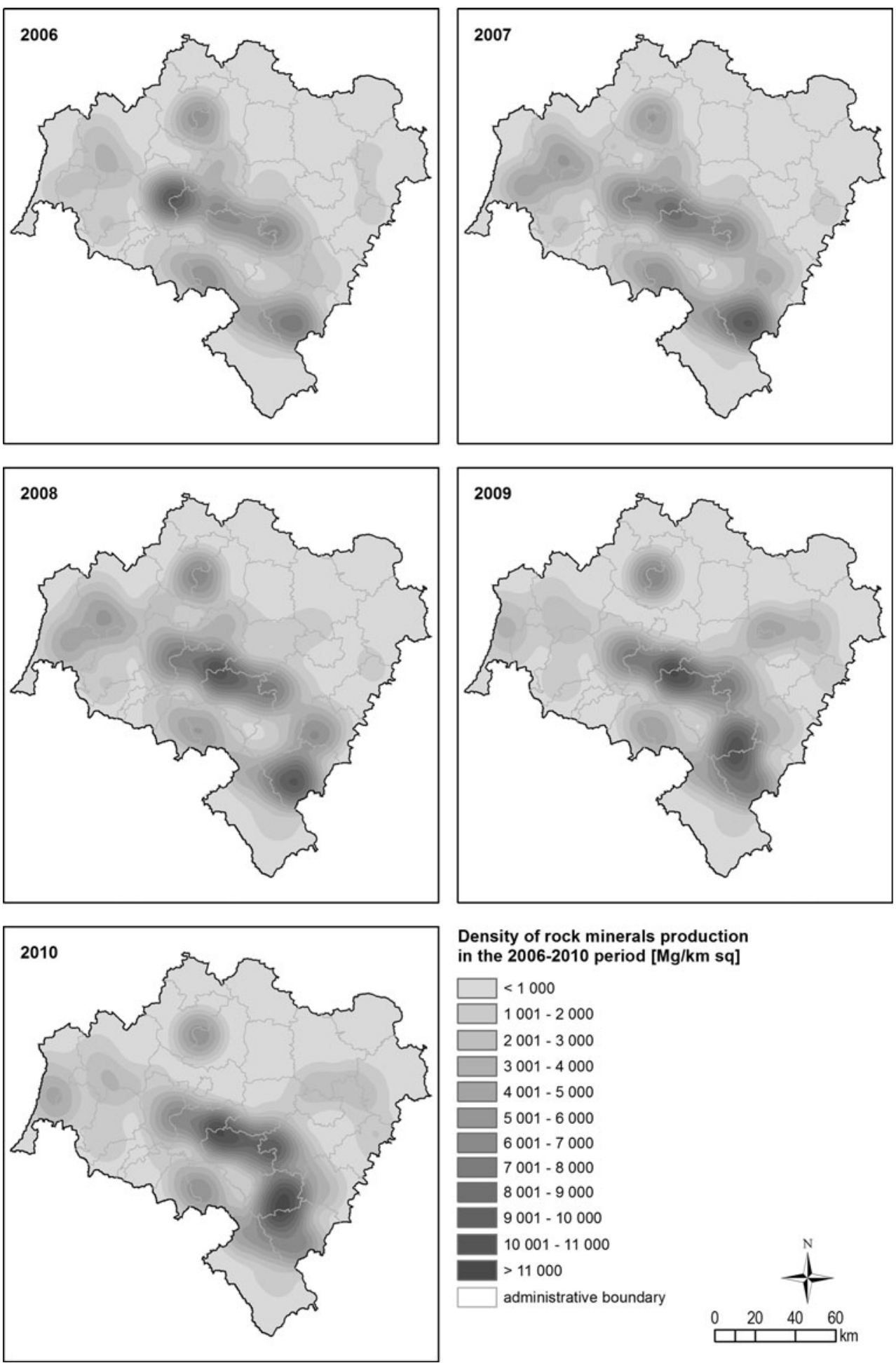

Density of rock minerals production in the 2006-2010 period [Mg/km sq]

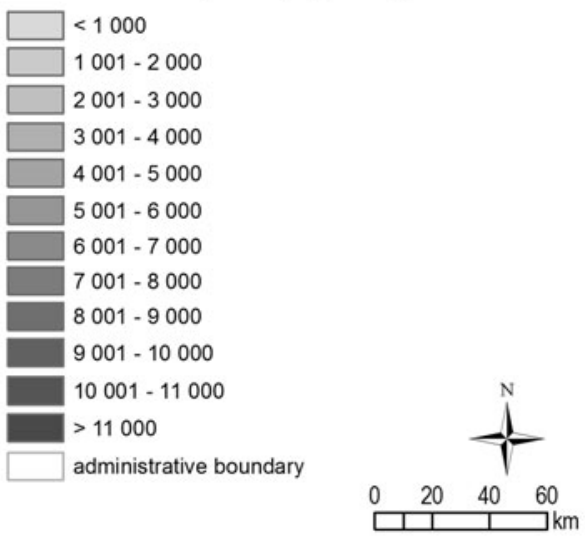

Scale of road transport flows for aggregates

The proposed methodology of analysing the magnitude of road traffic generated by transport of aggregates, described in "Scale of road transport flows for aggregates", has been developed to overcome the problem of the lack of information on the number of aggregates haulage trucks in periodic surveys of road traffic.

Analysis of the source data shows that out of the total number of 300 operating quarries, 213 use trucks only, 39 use railway but need to transport rock minerals to a nearby loading point using trucks, 17 use railway only, and 1 
quarry uses rail, with a conveyor belt to the railway loading point system.

The spatial distribution of the origins of aggregates transported by road has been shown as graduated symbols in the maps in Figs. 3 and 4. The first map shows quarries using road transport only; the second one shows quarries using both rail and road transport. The size of the symbol on the map represents the magnitude of the source in trucks per day. In the analysed year (2010), there were 17 quarries needing more than 100 trucks per day and 28 requiring more than 50. The largest operations generate traffic on public roads of between 200 and 500 trucks (this does not take into account the return trip). The highest concentration of origins of relevant road traffic flows exists in the central part of the Lower Silesia region. These transport flows begin on local roads and are then taken onto regional and national roads that are used to move aggregates to delivery sites. This has been shown in Fig. 5 on a map representing the number of trucks per unit area $\left(\mathrm{km}^{2}\right)$ needed to transport aggregates from the quarries using road transport only. These identified zones of intensive road transport are located in the eastern and central parts of the region where longitudinal and latitudinal transport belts can be distinguished. These are congruous with the zones of quarry production (Fig. 2).

Potential of railways to transport aggregates

Analysis of the potential for railways to transport aggregates shows that there are presently 69 quarries using road

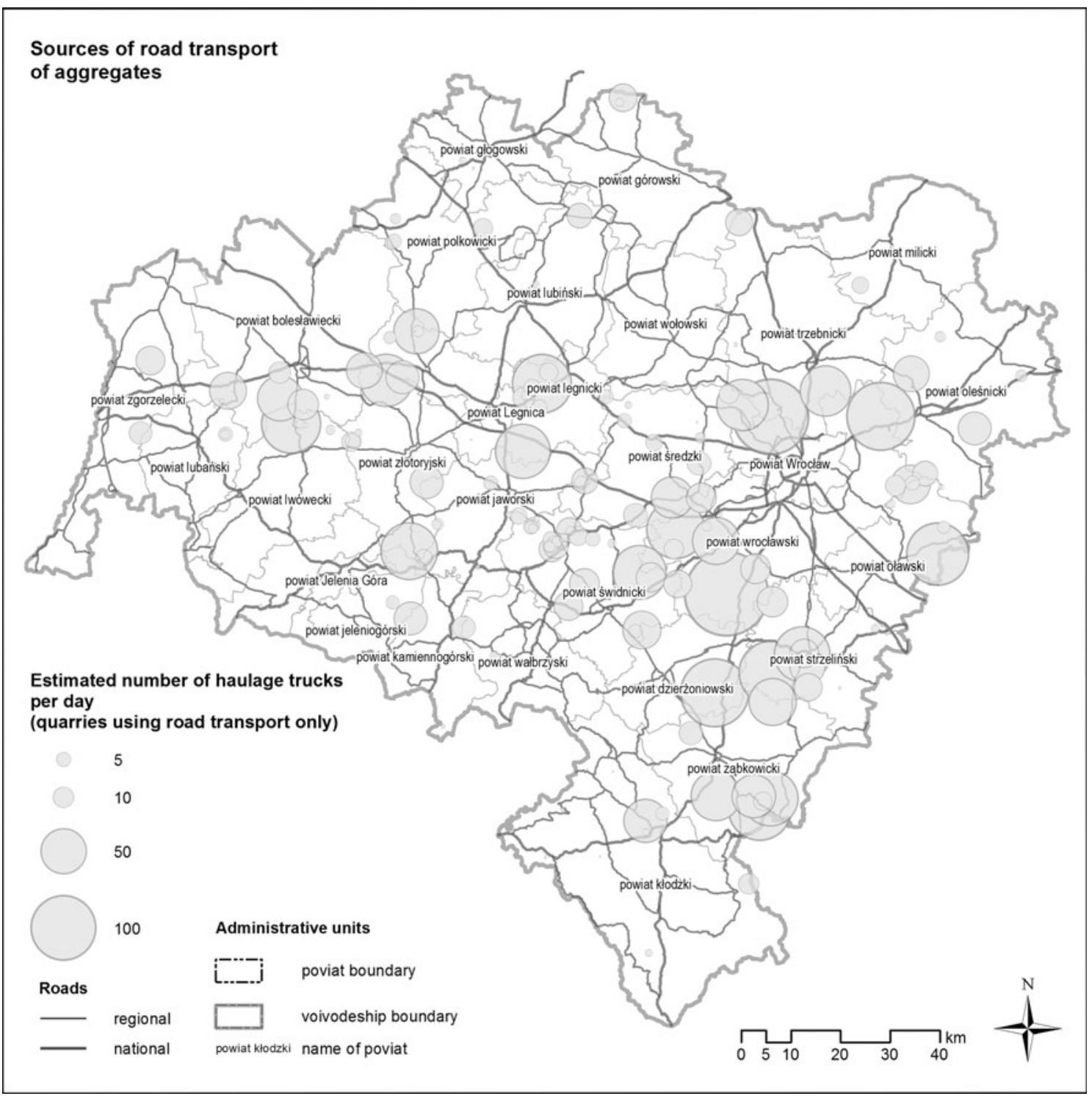

Fig. 3 Size and spatial distribution of the origins of road transport of aggregates (quarries with road transport system) 


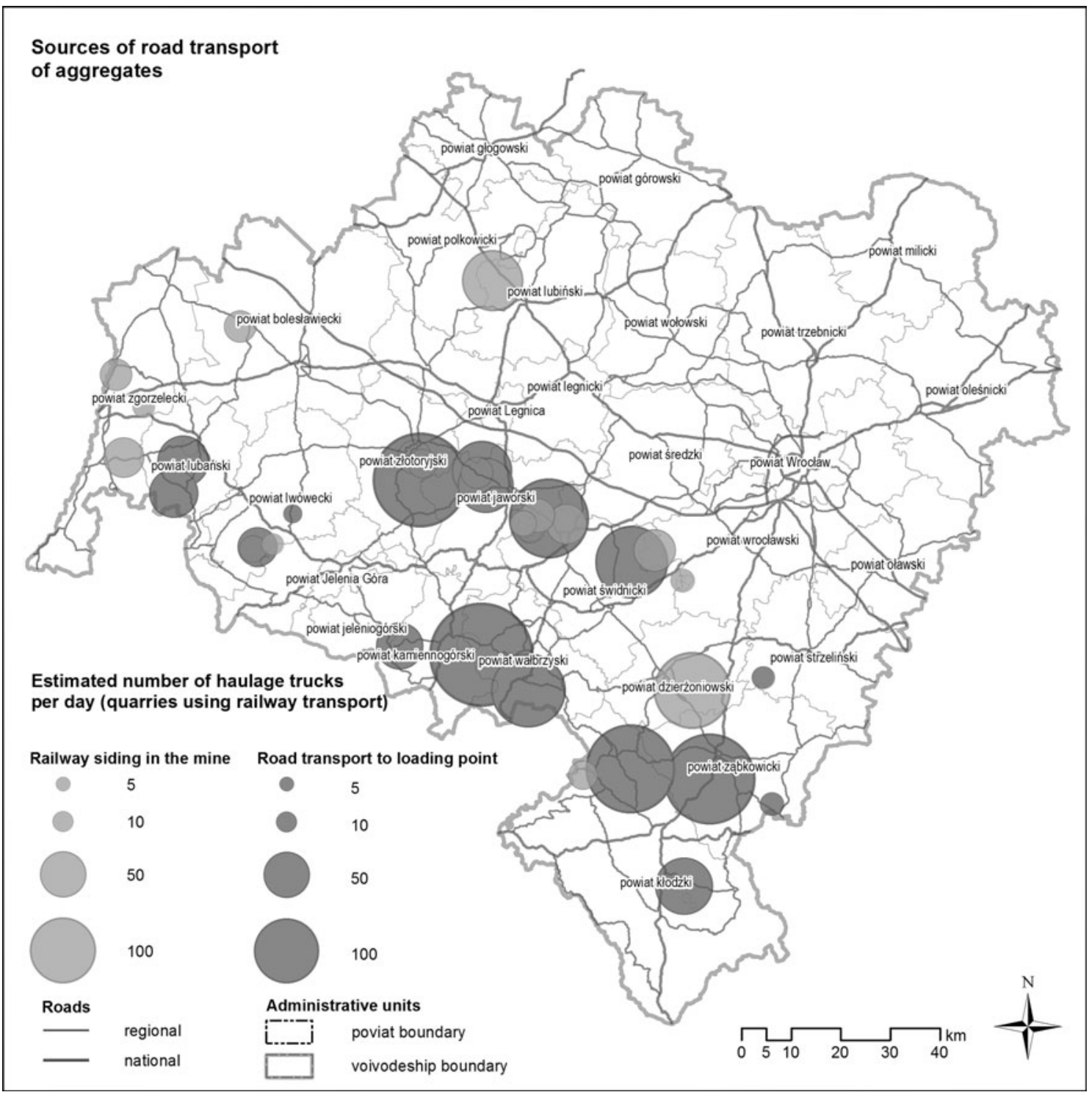

Fig. 4 Size and spatial distribution of the origins of road transport of aggregates (quarries with mixed transport systems)

transport only within the radius of up to $5 \mathrm{~km}$ from the 56 existing railway loading points. In 2010,51 of these mines were in operation. Their output amounted to $1 / 3$ of the total production of quarries using road transport only, which corresponds to approximately 1,000 trucks per day (Table 2). This load could theoretically be moved using the rail transport option.

It has to be taken into account that this analysis concentrates on spatial aspects and does not take into account economic factors in the road and rail transport of aggregates. However, conversion to a mixed form of transport or change to conveyor belt transport systems would significantly reduce the impact on road traffic for even the nearest of quarrying operations.

\section{Sufficiency of aggregates reserves}

In this paper, the scenario of maintaining current production averaged from data for the last 5 years has been presented. The analysis has been carried out separately for dimension and crushed stones, sands and gravels, and clay minerals. Figure 6 shows the estimated availability of economic reserves in place (industrial resources) or category 221 resources (UNCF-2009 classification) for already developed deposits; this is given in years of exploitation and their spatial location in the region.

The results indicate the available reserves of important magmatic and metamorphic rock minerals: granites, gabbro, and melaphyres, exceed 100 years; reserves of basalts, 


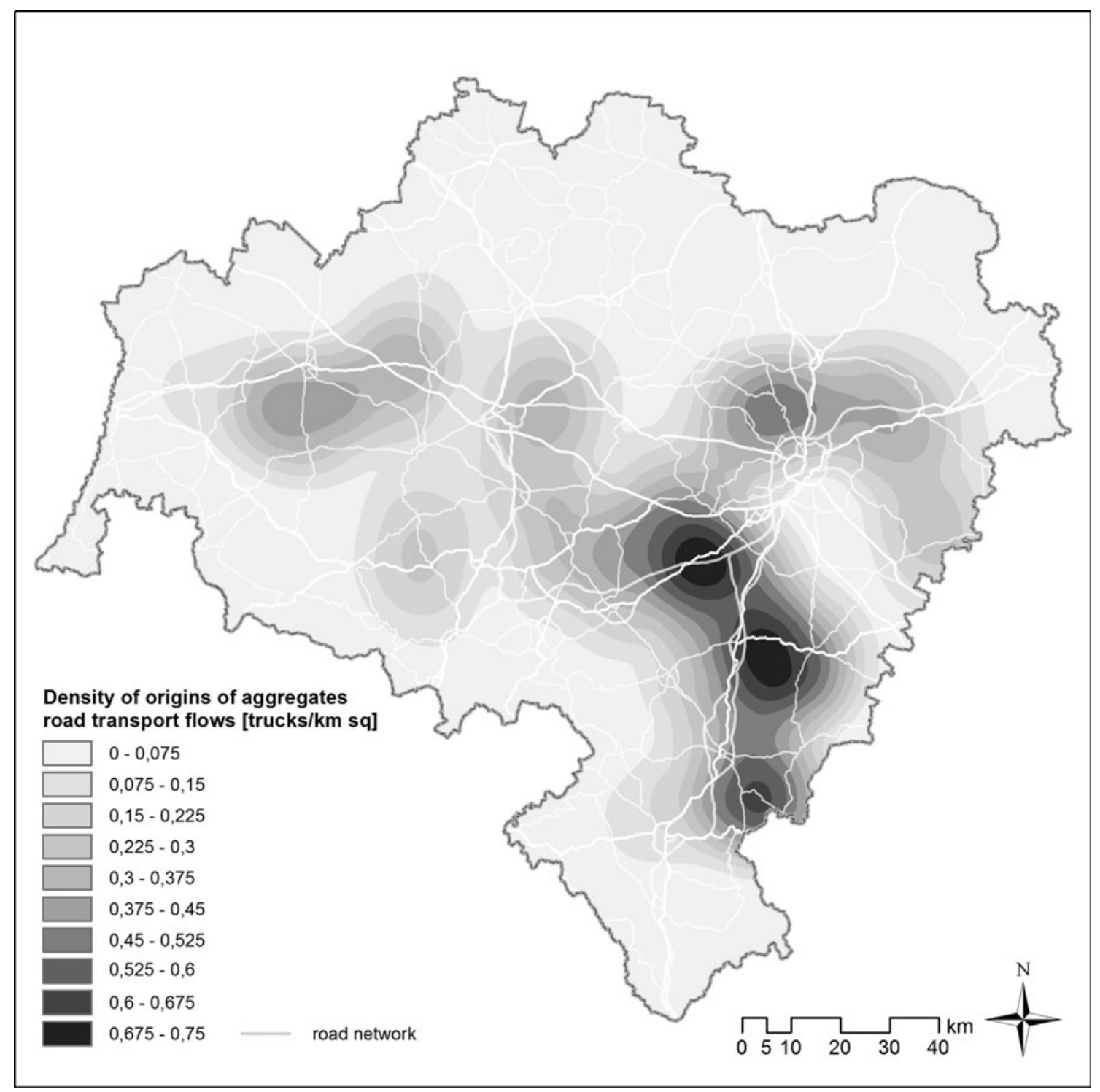

Fig. 5 Density of origins of aggregates road transport flows (trucks/km sq) in 2010

Table 2 Aggregates quarries using road transport and located up to $5 \mathrm{~km}$ from railway loading points

\begin{tabular}{|c|c|c|c|c|c|}
\hline Distance from railway loading point & $1 \mathrm{~km}$ & $2 \mathrm{~km}$ & $3 \mathrm{~km}$ & $4 \mathrm{~km}$ & $5 \mathrm{~km}$ \\
\hline Number of quarries using road transport & 12 & 33 & 49 & 55 & 69 \\
\hline Number of quarries producing aggregates in 2010 & 8 & 26 & 38 & 42 & 51 \\
\hline Output (tonnes) & $1,288,425$ & $3,162,650$ & $4,379,807$ & $5,812,718$ & $7,128,888$ \\
\hline Estimated number of truck per day & 182 & 446 & 618 & 820 & 1006 \\
\hline Percentage of total output of quarries using road transport (2010) & $6.0 \%$ & $14.8 \%$ & $20.4 \%$ & $27.1 \%$ & $33.3 \%$ \\
\hline Percentage of total output of all quarries (2010) & $2.6 \%$ & $6.4 \%$ & $8.8 \%$ & $11.7 \%$ & $14.4 \%$ \\
\hline
\end{tabular}

gneisses, and migmatites exceed 50 years; while amphibolites and serpentinites will last for at least 20 years at the present level of production (Fig. 7).
In the case of the 67 operating sand and gravel pits, 8 have reserves for more than 50 years, 9 for over 25 years, 18 between 11 and 25 years, and 32 for up to 10 years (Fig. 8). 


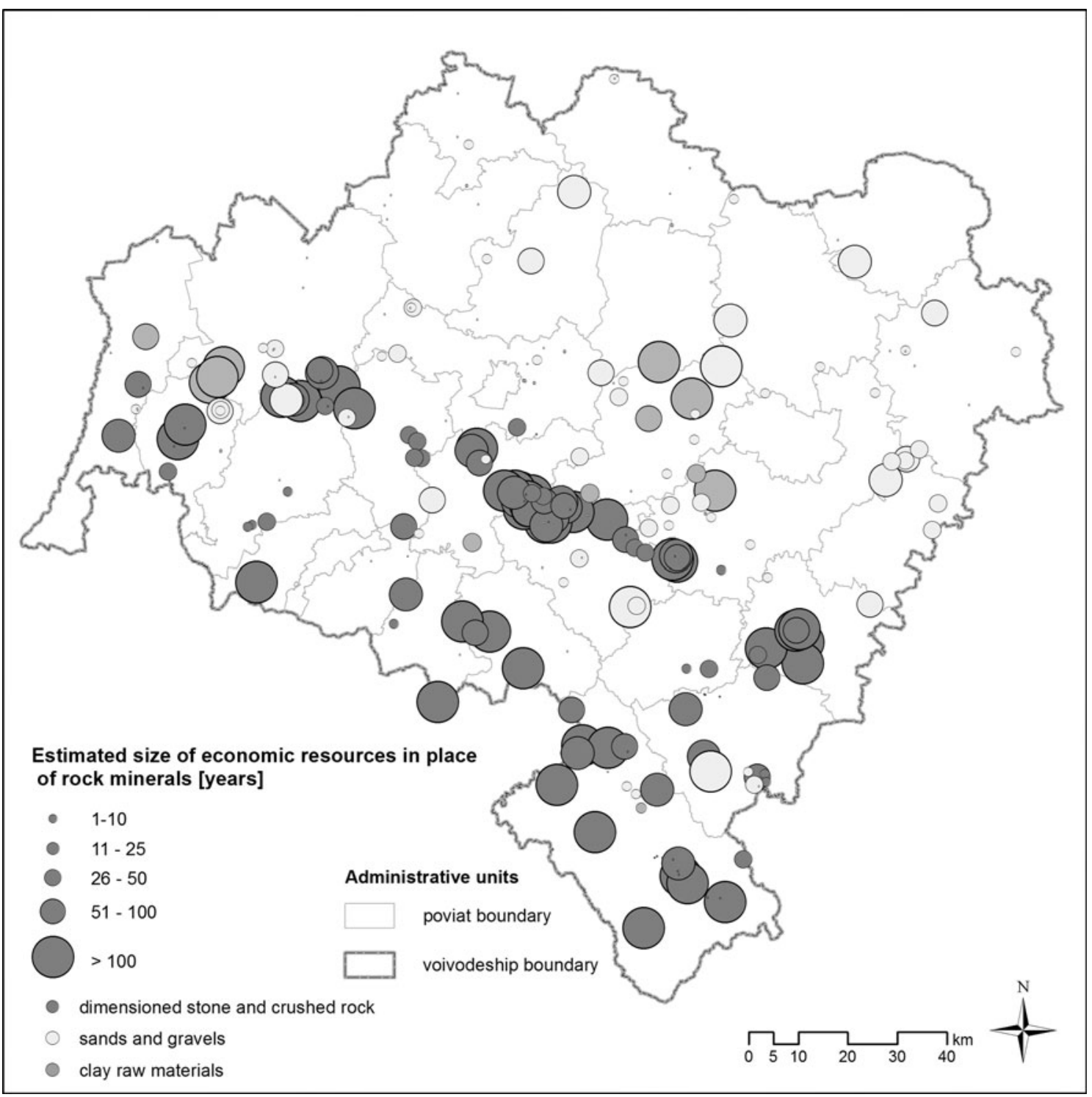

Fig. 6 Size and spatial distribution of the economic reserves of rock mineral deposits

These results give an approximate estimation of the available reserves without the need to open up new quarrying operations. The expected production life of mine may be extended if the output decreases with time or additional reserves are found.

\section{Valorisation of aggregates deposits}

The spatial development and management of an area may restrict or exclude from potential future exploitation some undeveloped but identified deposits. Valorisation provides a measure of the value of deposits and the basis for protection of the most valuable ones and withdrawal from protection of the least valued. This should result in a balance between the need for other forms of spatial development and preservation of rock mineral deposits for future use. Information on the availability of reserves from operating mines (part 4.4) provides an additional criterion to be taken into account.

Applying the analytical cartographic model (part 3.5), 68 undeveloped deposits in the Lower Silesia region have been selected and each one has been assigned a four symbol score representing their suitability for future development in terms of: the environmental constraints, availability of transport networks, current land use, and quantity and quality of mineral reserves. This score together with detailed characteristics of each deposit is important information for regional authorities in the process of granting licenses to extract minerals from deposits.

The results of this analysis show that future exploitation of many identified aggregates deposits may be prohibited—category C (25 deposits) or limited—category B (40) 


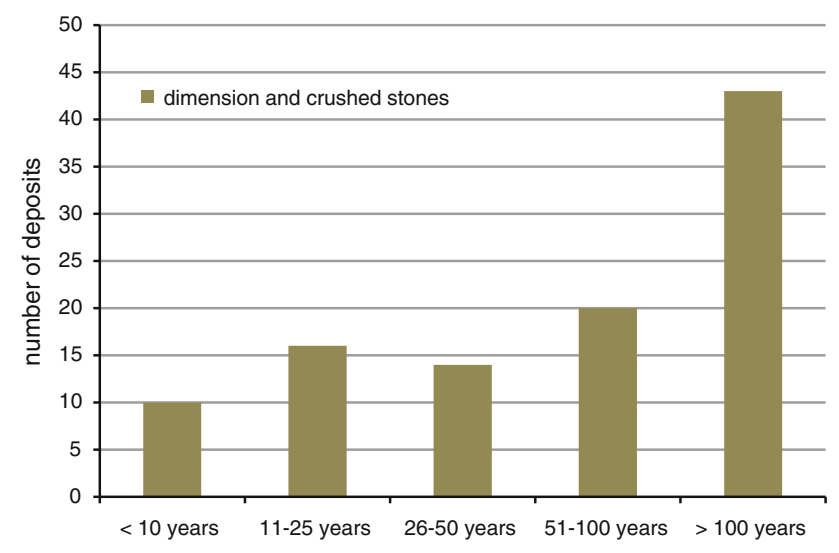

Fig. 7 Estimated availability of the economic reserves of dimension and crushed stones quarries in the Lower Silesia region

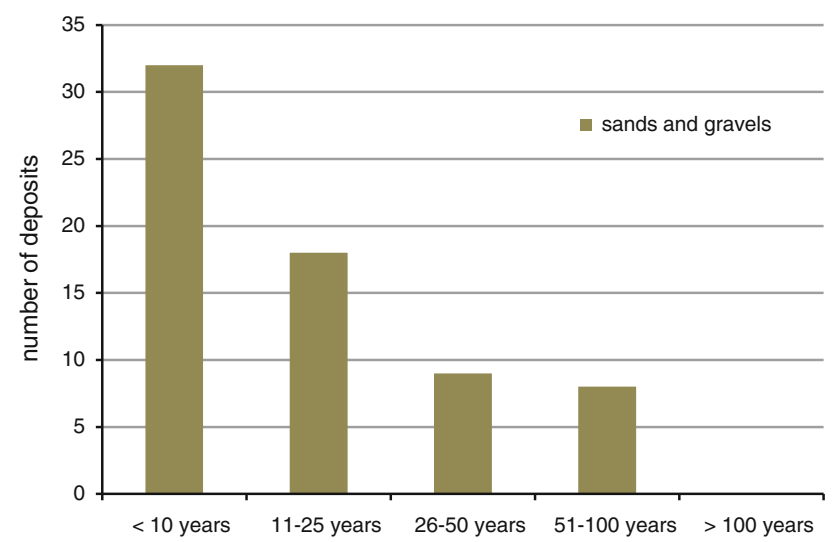

Fig. 8 Estimated availability of economic reserves of sand and gravel mines in the Lower Silesia region

mainly because of environmental protection considerations. The remaining ones (13) have been assigned category A.

\section{Conclusions}

The research focused on the analysis of the identification, exploitation and transport of aggregates minerals, using the example of the Lower Silesia region in Poland. Attention has been given to spatial and temporal changes in the distribution and intensity of the quarrying and road transport of aggregates, as well as the availability of these mineral resources in the future and the potential of railways as alternative means of transport. The study has been facilitated by the use of GIS and cartographic models developed with the aim of streamlining the analytical process.

The study has produced maps and reports showing changes, for the period of the last 5 years (2006-2010), in the spatial distribution of aggregates production and road transport. It has been found that quarries in the region occur in roughly longitudinal bands and that a small, gradual shift of the zones of intensive production towards the east has taken place. The following phenomena have been observed: the concentration of small quarries and pits in relatively small areas associated with rock massifs (e.g., granite in the central part of the region) and the development of very large, single mines exploiting deposits on a massive scale.

The potential of the existing railway infrastructure to take over part of the road transport streams for aggregates has been analysed; this possibility has been observed at 69 quarry locations, of which 51 are active.

In addition to the above, the availability of aggregates reserves in already developed deposits at different production levels has been analysed. A simplified valorisation of undeveloped deposits to determine their potential value for mining has been carried out. The economic reserves of most types of dimension and crushed stones will last for several dozen years and in some cases for over 100 years. The possibility of developing many deposits is constrained by environmental protection requirements.

The research has been conducted with the aim of providing regional authorities with information upon which to base the management of regional aggregates resources and the various economic, social, and environmental impacts of their exploitation. The results have been used in drafting up projects of the revised spatial development plan and spatial development strategy to define principles, aims and directions of mineral resources management in the region. In addition, the programme of adaptation of the railway infrastructure in Lower Silesia, which identifies critical railway lines, has also used the results of the density of rock raw material transport and mine proximity to loading stations analyses.

Acknowledgments Parts of this work has been developed within the Project Study of mining and transport of rock minerals in Lower Silesia. Second edition in the Regional Bureau of Spatial Planning in Wroclaw, a unit of the Lower Silesian Marshal's Office.

Open Access This article is distributed under the terms of the Creative Commons Attribution License which permits any use, distribution, and reproduction in any medium, provided the original author(s) and the source are credited.

\section{References}

Bagdanavičiūtė I, Valiūnas J (2012) GIS-based land suitability analysis integrating multi-criteria evaluation for the allocation of potential pollution sources. Environ Earth Sci 68(6):1797-1812

Blachowski J (2011) State and perspectives of rock mineral mining and transport in the space of the Lower Silesia Voivodeship. Mining Rev 10 (1067). 66:114-123 
Blachowski J, Korzeń J, Mańkowska-Bigus K (2012) Study of mining and transport of rock minerals in the Lower Silesia, regional bureau of spatial planning in Wroclaw, 2nd edn. Lower Silesia Marshal Office, Wroclaw (in Polish)

Central Statistical Office (2011) Environment 2011, Statistical Information and Elaborations. Central Statistical Office, Warsaw

Epanechnikov VA (1969) Non-parametric estimation of a multivariate probability density. Theory Probability Appl 14:153-158

Heywood I, Cornelius S, Carver S (2006) An introduction to geographic information system, 3rd edn. Prentice Hall, Pearson

Huang S, Li X, Wang Y (2012) A new model of geo-environmental impact assessment of mining: a multiple-criteria assessment method integrating Fuzzy-AHP with fuzzy synthetic ranking. Environ Earth Sci 66:275-284

Jordan G (2009) Sustainable mineral resources management: from regional mineral resources exploration to spatial contamination risk assessment of mining. Environ Geol 58:153-169

Kabziński A (2012) Forecast of demand and production of natural aggregates in Poland in the 2012-2020(+2) period, Polish Association of Aggregates Producers. Aggregates 1:22-27 (in Polish)

Kennedy M (2009) Introducing geographic information systems with ArcGIS, 2nd edn. Wiley, New York
Łochańska D, Stryszewski M (2011) Logistics considerations as for satisfying a demand for rock material depending on its kind, quality as well as optimization of roads and resources. Open-pit Mining Magazine LII:96-99 (in Polish)

McCoy J, Johnston K, Knopp S, Borup B, Willison J (2004) ArcGIS Spatial Analyst. ESRI, Redlands

Nieć M, Radwanek-Bạk B (2011) The complex valorisation and classification of rock mineral deposits. Open-pit Mining Magazine LII:5-14 (in Polish)

Polish Geological Institute (2011) Mineral resources of Poland. http://geoportal.pgi.gov.pl/surowce. Accessed 15 August 2012

Radwanek-Bạk B (2007) The concept of multi-criteria mineral resources protection. Environ Geol 52:137-145

Tomlin CD (2008) Cartographic modelling. In: Kemp KK (ed) Encyclopedia of geographic information science. Sage, California

United Nations (2010) United nations framework classification for fossil energy and mineral reserves and resources 2009. ECE Energy Series No. 39. New York and Geneva. http://www.unece. org/energy/se/unfc_2009.html. Accessed 23 November 2012

Vrba J, Moldan B (1989) Integrated Use of Natural Resources and Geoenvironment. Environ Geol Water Sci 14(3):159-165 